\title{
Sperm Migration and Selection in the Reproductive Tract of Female Mice is Mostly Affected by Male Genotype
}

\author{
Katarzyna KOTARSKA and Małgorzata LENARTOWICZ
}

Accepted October 5, 2010

\begin{abstract}
KOTARSKA K., LENARTOWICZ M. 2011. Sperm migration and selection in the reproductive tract of female mice is mostly affected by male genotype. Folia biologica (Kraków) 59: 71-75.

The aim of the present study is to assess the influence of male and female genotypes on the transport of sperm to the site of fertilization. We mated B10.BR, B10.BR-Y ${ }^{\text {del }}$ and BALB/c males with $B 10 . B R$ and $B A L B / c$ females and then analyzed the quality and quantity of spermatozoa found five hours post coitus in three successive parts of the female reproductive tract. We found that B10.BR and B10.BR-Y ${ }^{\text {del }}$ spermatozoa are very effectively selected by the uterotubal junction and other barriers of the female genital tract. On the contrary, severely deformed BALB/c spermatozoa appeared to be able to cross selective barriers and were present both in oviducts and in cumulus oophorus. It cannot be excluded that these morphologically abnormal male gametes take part in fertilization. B10.BR- $Y^{\text {del }}$ spermatozoa were very rarely observed above the uterotubal junction. This shows that in vivo they migrate with delay and with difficulties pass the border between uterus and oviducts. This finding is in agreement with previous in vitro analyzes, which revealed many irregularities in movement of B10.BR-Y ${ }^{\text {del }}$ spermatozoa. Sperm quality and quantity in the reproductive tracts of B10.BR and BALB/c females were convergent if they were mated with males belonging to one strain, proving that migration and selection of spermatozoa in the female genital tract depend mostly on male genotype.
\end{abstract}

Key words: Female reproductive tract, uterotubal junction, spermatozoa, sperm selection, sperm migration, sperm head morphology.

Katarzyna KOTARSKA, Malgorzata LENARTOWICZ, Department of Genetics and Evolution, Institute of Zoology, Jagiellonian University, R. Ingardena 6, 30-060 Kraków, Poland. E-mail: katarzyna.kotarska@uj.edu.pl

To take part in fertilization, spermatozoa must complete a long arduous journey through the female reproductive tract and cross a sequence of selective barriers lying on their way to eggs. In mice, which belong to species with uterine deposition of semen, the uterotubal junction is the primary barrier limiting access to the oviducts. Only those spermatozoa exhibiting progressive linear movement and the ability to attach to the oviductal epithelium can penetrate the uterotubal junction and enter the lower part of the fallopian tube named the isthmus (SHALGI et al. 1992; SCOTT 2000; HOLT \& VAN LOOK 2004; NAKANISHI et al. 2004). At the beginning of the isthmus, male gametes possessing proper receptors on their surfaces are bound by the oviductal epithelium creating a sperm reservoir. This is considered as the next step in sperm selection. Thanks to factors derived from the female genital tract, spermatozoa adhering to epithelial cells are preserved in viability and gradually undergo a number of physiological changes termed capacitation. During capacitation male gametes lose surface molecules responsible for their attachment to the oviductal epithelium. As a result of hyperactivated motility, capacitated (thus fertilization competent) spermatozoa are released from the isthmic reservoir and are able to continue their journey towards eggs (DEMOTT \& SUAREZ 1992; OLDS-CLARKE 1996; SUAREZ 1998; SCOTT 2000; TALEVI \& GUALTIERI 2004). A small number of male gametes which successfully reach the ampulla must overcome the last two barriers separating them from oocytes. Each oocyte is surrounded by an outer layer of cumulus granulosa cells (cumulus oophorus) and an inner glycoprotein structure - zona pellucida (PRIMAKOFF \& MYLES 2002). Both these egg investments are very effective in preventing abnormal spermato- 
zoa from taking part in fertilization (KRZANOWSKA \& LORENC 1983).

It has been shown that the velocity and effectiveness of spermatozoa in penetrating selective barriers within the female genital tract depend strongly on male genotype. Both autosomal genes and genes linked with the $\mathrm{Y}$ chromosome decide on the functional competence of male gametes (TESSLER \& OLDS-ClARKE 1981; KRZANOWSKA 1986). On the other hand, the female reproductive tract actively interacts with spermatozoa during their migration towards oocytes and for this reason the female genotype also influences this process (NICOL \& MCLAREN 1974; FAZELI et al. 2004). The aim of the present study is to assess the degree in which male and female genotypes determine the transport of sperm to the site of fertilization. For this purpose we mated B10.BR, B10.BR- $Y^{\text {del }}$ and BALB/c male mice with females of their own or the alternative strain. Then we analyzed the quality and quantity of spermatozoa present about five hours post coitus in different parts of the female genital tracts. Males of all three strains produce a high percentage of morphologically abnormal gametes and that is why they were a good model for our analysis. The morphology of spermatozoa, especially the head shape, is often used as an indirect indicator of their functional quality. B10.BR- $Y^{\mathrm{del}}$ males, genetically identical to B10.BR males but with a large deletion in the long arm of their $\mathrm{Y}$ chromosome, show particularly common sperm head deformations (64.2-88\%), often with a typical flattening of the acrosomal cap. Males of the congenic B10.BR strain produce sperm with a definitely lower proportion of misshapen gametes (22.6-30.7 \%) (STYRNA 1991; STYRNA et al. 1991a,b; STYRNA et al. 2002). For BALB/c males this proportion was estimated as high as about $75 \%$ (BUDA \& KRZANOWSKA 1975; BURRUEL 1996).

\section{Material and Methods}

All animals used in the experiment were bred at the Department of Genetics and Evolution of Jagiellonian University. Male mice from three in- bred strains: B10.BR, B10.BR-Y ${ }^{\text {del }}$ and BALB/c were mated with $\mathrm{B} 10 . \mathrm{BR}$ and $\mathrm{BALB} / \mathrm{c}$ females. Adult, 3-5 months old animals, maintained under a $12 \mathrm{~h}$ light-dark cycle, were caged in individual pairs (5-7 pairs for each type of mating). Females with a vaginal plug were killed by cervical dislocation approximately five hours post coitus and their reproductive tract was removed. The oviducts were severed from the uterus at a point directly above the uterotubal junction. Uterine and oviductal contents were then prepared separately.

A small amount of fluid taken from the incised uterus was put on a slide and a smear was prepared and air dried. Oviducts were placed on another slide in individual drops of PBS. The ampullar wall of each oviduct was opened with a needle allowing the cumulus-oocyte complexes to flow out into the liquid. Oocytes were transferred to drops of PBS containing bovine testicular hyaluronidase (Sigma-Aldrich, Germany) in a concentration allowing for complete dispersal of cumulus cells (50 $\mathrm{IU} / \mathrm{ml}$ ). The remaining oviducts were flushed with a small amount of PBS using a thin pipette inserted into their uterine end. Drops with oviductal content and with ova were air dried. All preparations were then fixed for $1 \mathrm{~h}$ in acetic alcohol (absolute methanol and glacial acetic acid, 3:1, v/v), stained with a $1 \%$ aqueous solution of eosin $\mathrm{Y}$ (Wako, Japan), dehydrated in alcohol, cleared with xylene and analyzed under a light microscope. Sperm head morphology in uteri, oviducts and in cumulus oophorus was classified according to STYRNA et al. (1991), as normal, slightly deformed (class 1a, 1b), or strongly deformed (class 2, 3, 4) (Fig. 1). Spermatozoa found in oviducts and in egg investments were additionally counted.

For statistical analysis results obtained in percentages were normalized using angular transformation. Differences between groups were evaluated by a Student's $t$-test. A P value below 0.05 was considered statistically significant.

Experiments were performed in accordance with Polish legal requirements, under the licence of the Local Ethics Commision for Animal Experiments.

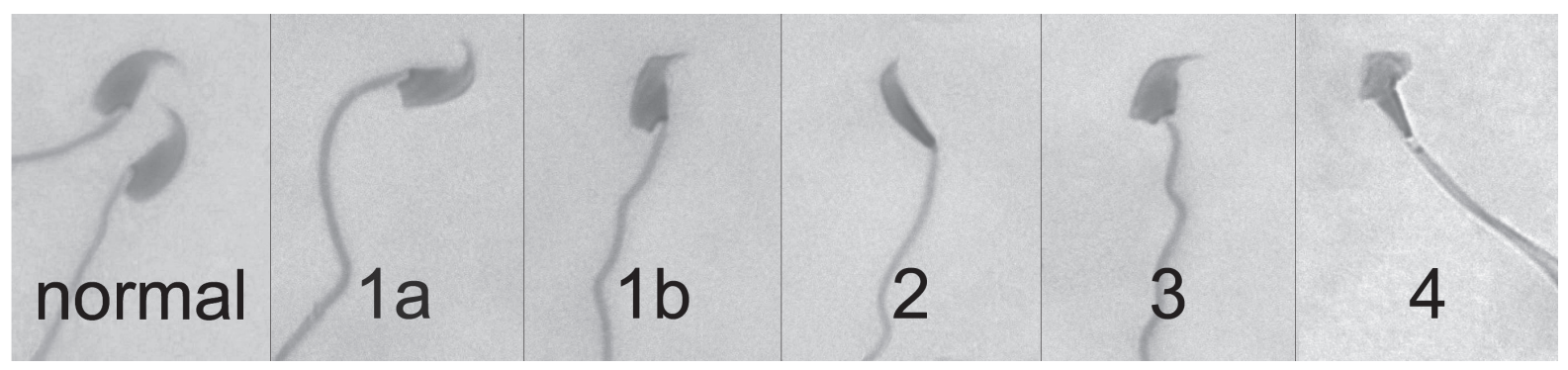

Fig. 1. Typical examples of sperm head abnormalities according to the classification of STYRNA et al. (1991). 


\section{Results and Discussion}

The proportion of morphological abnormalities among spermatozoa recovered from reproductive tracts of $\mathrm{B} 10 . \mathrm{BR}$ and $\mathrm{BALB} / \mathrm{c}$ females is presented in Figures 2 and 3. For all six types of mating, the frequency of sperm head deformations observed in the oviductal flushings was greatly reduced in comparison with the uterine content (the difference is statistically significant, $\mathrm{P}<0.002$ ). This reduction resulted from eliminating strongly abnormal spermatozoa on the border between the uterus and oviducts. Slightly deformed male gametes were equally numerous in both these parts of the female genital tracts. This observation strongly confirms that in the reproductive tract of female mice the uterotubal junction plays a key role in selection of male gametes migrating towards eggs. It effectively eliminates severely deformed spermatozoa, allowing normal or slightly misshapen gametes to pass (KRZANOWSKA 1974; STYRNA et al. 2002).

Between the uteri and oviducts the gradient in sperm quality was very high, whereas above the uterotubal junction it persisted at a similar level. Among spermatozoa present in the cumulus oophorus, head deformations were identified with practically the same frequency as in the oviductal flushings. We conclude that in vivo oviductal barriers and egg investments have less influence on sperm selection. Probably most spermatozoa able to cross the uterotubal junction can also force all additional obstacles separating them from oocytes and compete for fertilization.

When females of both B10.BR and BALB/c strains were mated with $\mathrm{BALB} / \mathrm{c}$ males, the proportion of severely misshapen spermatozoa in their oviducts and near eggs was much higher than in matings with B10.BR or B10.BR-Y ${ }^{\mathrm{del}}$ males $(18.14 \%$ versus $3.37 \%)$. This difference is statistically significant $(\mathrm{P}<0.03)$. This finding shows clearly that grossly deformed BALB/c spermatozoa are less effectively eliminated by selective barriers of the female genital tract in comparison with gametes of B10.BR and B10.BR-Y ${ }^{\text {det }}$ males. Because BALB/c spermatozoa with strong morphological abnormalities were identified quite often not only in oviducts but also between cumulus cells surrounding oocytes, it cannot be excluded that they take part in fertilization. It has been shown that many severely misshapen gametes of $\mathrm{BALB} / \mathrm{c}$ males carry all the genome and organelles necessary for normal embryonic development. When such spermatozoa were injected in vitro into mouse oocytes, they initiated the development of fully fertile matured individuals (BURRUEL et al.

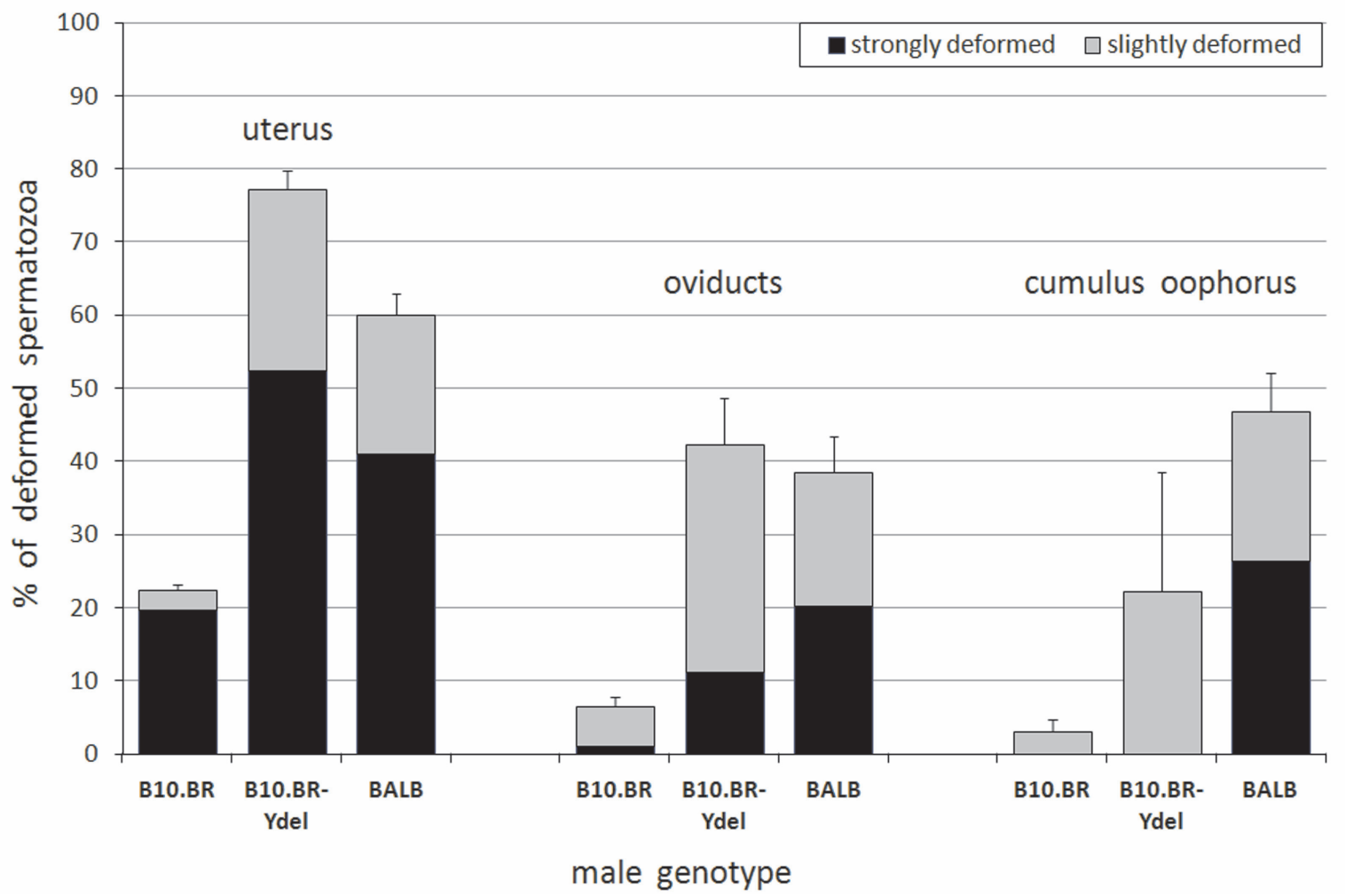

Fig. 2. Frequency (\%) of head deformations among spermatozoa recovered from the reproductive tracts of $\mathbf{B 1 0}$.BR females five hours after copulation with B10.BR, B10.BR-Y and BALB/c males (mean $\pm \mathrm{SE}$ ). 


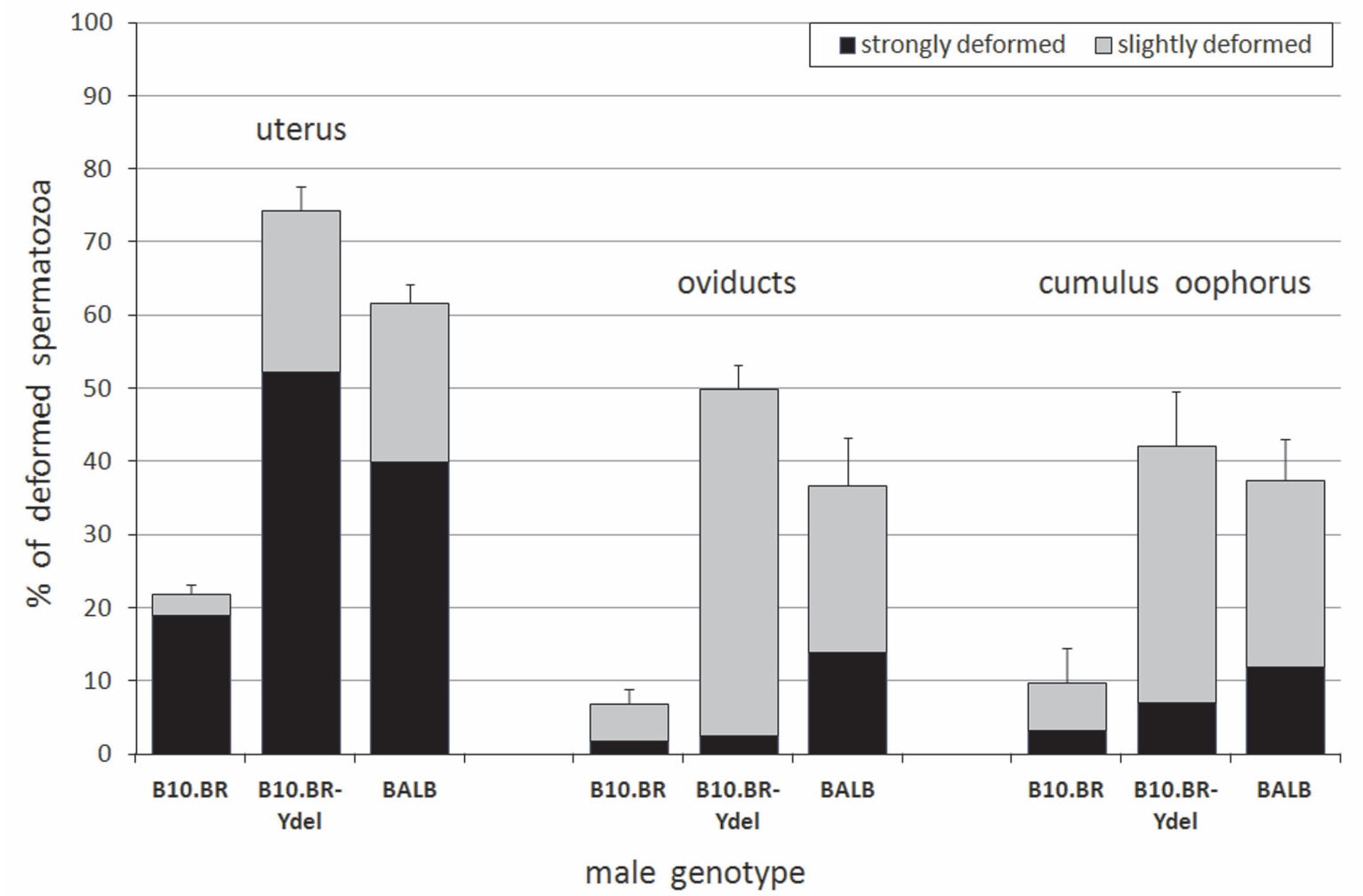

Fig. 3. Frequency (\%) of head deformations among spermatozoa recovered from the reproductive tracts of BALB/c females five hours after copulation with B10.BR, B10.BR-Y $Y^{\text {elel }}$ and BALB/c males (mean $\pm \mathrm{SE}$ ).

1996). There is also evidence that spermatozoa with grossly deformed heads are able to bound to zona pellucida (KOT \& HANDEL 1987). BALB/c males produce sperm with a very high proportion of morphologically abnormal gametes. It is probable that the ability of severely deformed BALB/c spermatozoa to cross selective barriers of females and to participate in fertilization is a kind of compensational mechanism which improves the reproductive efficiency of the strain. This ability additionally indicates that abnormalities in sperm head morphology do not always cause disorders in their functioning.

In the oviductal flushings and in egg investments the number of observed spermatozoa was highly variable (Table 1), but one regularity was noted. Gametes of B10.BR- $Y^{\text {del }}$ males were very rare in upper parts of the female reproductive tracts. In some cases not a single spermatozoon was found in the oviducts despite a dense concentration of sperm in the uterus. This shows that gametes of B10.BR- $Y^{\text {del }}$ males migrate with delay in the female genital tract and have problems with crossing the uterotubal junction. It is known that passing through the uterotubal junction requires an appropriate kind of motility from spermatozoa (SHALGI et al. 1992; SCOTT 2000; HOLT \& VAN LOOK 2004). GRZMIL et al. (2007), using the computer assisted
Table 1

Number of spermatozoa found above the uterotubal junction of B10.BR and BALB/c females five hours after copulation with B10.BR, B10.BR-Y $Y^{\text {del }}$ and $\mathrm{BALB} / \mathrm{c}$ males (mean $\pm \mathrm{SE}$ )

\begin{tabular}{|c|c|}
\hline $\begin{array}{l}\text { Type of mating } \\
\text { (female genotype } \times \\
\text { male genotype) }\end{array}$ & $\begin{array}{l}\text { Mean number of sper- } \\
\text { matozoa in oviducts } \\
\text { (including these between } \\
\text { cumulus cells) } \pm \mathrm{SE}\end{array}$ \\
\hline $\mathrm{B} 10 . \mathrm{BR} \times \mathrm{B} 10 . \mathrm{BR}$ & $74.27^{\mathrm{a}} \pm 14.95$ \\
\hline $\mathrm{B} 10 . \mathrm{BR} \times \mathrm{B} 10 . \mathrm{BRY} \mathrm{del}^{\mathrm{del}}$ & $6.15^{\mathrm{b}} \pm 1.9$ \\
\hline $\mathrm{B} 10 . \mathrm{BR} \times \mathrm{BALB}$ & $78.92^{a} \pm 15.87$ \\
\hline $\mathrm{BALB} \times \mathrm{B} 10 . \mathrm{BR}$ & $64.61^{\mathrm{a}} \pm 14.89$ \\
\hline $\mathrm{BALB} \times \mathrm{B} 10 . \mathrm{BRY}^{\mathrm{del}}$ & $18.08^{\mathrm{c}} \pm 5.49$ \\
\hline BALB $\times$ BALB & $45^{\mathrm{a}, \mathrm{c}} \pm 12.77$ \\
\hline
\end{tabular}

a, b, c : values with different superscripts are significantly different $(\mathrm{P}<0.05)$.

semen analysis system (CASA) proved in vitro that gametes of $\mathrm{B} 10 . \mathrm{BR}-\mathrm{Y}^{\mathrm{del}}$ males demonstrate a decrease of many movement parameters. Deletion in the long arm of the Y chromosome affects velocity parameters (VAP, VCL, VSL), parameters 
describing sperm head activity during movement (ALH, BCF) and linearity of movement (LIN). This explains the very slow and inefficient migration of B10.BR- $\mathrm{Y}^{\mathrm{del}}$ spermatozoa in the physiological conditions of our experiment.

The quality of spermatozoa found in the reproductive tracts of B10.BR and BALB/c females was absolutely convergent when they were mated with males belonging to one strain. The only significant difference $(\mathrm{P}=0.01)$ was observed for $\mathrm{BALB} / \mathrm{c}$ spermatozoa present near oocytes of the females. In the cumulus layer surrounding oocytes of B10.BR females, strong deformations of BALB/c spermatozoa were discovered with over a twofold higher frequency than near eggs of BALB/c females (Figs $2 \& 3$ ). There are no differences in the quantity of spermatozoa in oviducts between females mated with males from one strain (Table 1). We noticed only that slightly more gametes of B10.BR-Y $Y^{\text {del }}$ males cross the uterotubal junction when they migrate in the reproductive tract of $\mathrm{BALB} / \mathrm{c}$ females (the difference is statistically significant in comparison with B10.BR females, $\mathrm{P}=0.04$ ). These results lead to the final conclusion that the migration velocity and the degree of selection of spermatozoa in the female genital tract depend mostly on male genotype. The female genotype may have, however, a modulatory influence on these processes.

\section{References}

BudA D., KRZANOwSKA H. 1975. Types of sperm head abnormalities in five inbred strains of mice (A, AKR, 129, C58, BALB). Zwierzęta lab. 15: 63-70.

BuRRUEL V. R., YANAGIMACHI R., WhitTEN W. K. 1996. Normal mice develop from oocytes injected with spermatozoa with grossly misshapen heads. Biol. Reprod. 55: 709-714.

DEMOTT R., SUAREZ S. S. 1992. Hyperactivated sperm progress in the mouse oviduct. Biol. Reprod. 46: 779-785.

Fazeli A., AfFara N. A., Hubank M., Holt W. V. 2004. Sperm-induced modification of the oviductal gene expression profile after natural insemination in mice. Biol. Reprod. 71: 60-65.

GrZMil P., Go€As A., Müller C., Styrna J. 2007. The influence of the deletion on the long arm of the Y chromosome on sperm motility in mice. Theriogenology 67: 760-766.

HolT W. V., VAN LOOK K. J. W. 2004. Concepts in sperm heterogeneity, sperm selection and sperm competition as biological foundations for laboratory tests of semen quality. Reproduction 127: 527-535.

KoT M. C., HANDEL M. A. 1987. Binding of morphologically abnormal sperm to mouse egg zonae pellucidae in vitro. Gamete Res. 18: 57-66.

KRZANOWSKA H. 1974. The passage of abnormal spermatozoa through the uterotubal junction of the mouse. J. Reprod. Fert. 38: 81-90.

KRZANOWSKA H. 1986. Interstrain competition amongst mouse spermatozoa inseminated in various proportions, as affected by the genotype of the Y chromosome. J. Reprod. Fert. 77: 265-270.

KRZANOWSKA H., LORENC E. 1983. Influence of egg investments on in-vitro penetration of mouse eggs by misshapen spermatozoa. J. Reprod. Fert. 68: 57-62.

NAKANISHI T., ISOTANI A., YAMAGUCHI R., IKAWA M., BABA T., SUAREZ S. S., OKABE M. 2004. Selective passage through the uterotubal junction of sperm from a mixed population produced by chimeras of calmegin-knockout and wild-type male mice. Biol. Reprod. 71: 959-965.

NiCOL A., MCLAREN A. 1974. An effect of the female genotype on sperm transport in mice. J. Reprod. Fert. 39: 421-424.

OLDS-CLARKE P. 1996. How does poor motility alter sperm fertilizing ability? J. Androl. 17: 183-186.

PrimaKofF P., MYles D. G. 2002. Penetration, adhesion, and fusion in mammalian sperm-egg interaction. Science 296: $2183-2185$.

SCOTT M. A. 2000. A glimpse at sperm function in vivo: sperm transport and epithelial interaction in the female reproductive tract. Anim. Reprod. Sci. 60-61: 337-348.

SHALGI R., SMITH T., YANAGIMACHI R. 1992. A quantitative comparison of the passage of capacitated and uncapacitated hamster spermatozoa through the uterotubal junction. Biol. Reprod. 46: 419-424.

STYRNA J. 1991. Influence of partial Y chromosome deletion and of autosomal genes on mouse sperm phenotype. Zesz. nauk. UJ CMLXXXII, Pr. Zool. 36: 25-55. (In Polish).

Styrna J., BilińsKa B., KRZANOWSKA H. 2002. The effect of a partial Y chromosome deletion in B10.BR-Y $\mathrm{Y}^{\mathrm{del}}$ mice on testis morphology, sperm quality and efficiency of fertilization. Reprod. Fertil. Dev. 14: 101-108.

Styrna J., IMAi H. T., MORIWAKi K. 1991a. An increased level of sperm abnormalities in mice with a partial deletion of the Y chromosome. Genet. Res. 57: 195-199.

StYRna J., KLAG J., MORIWAKI K. 1991b. Influence of partial deletion of the Y chromosome on mouse sperm phenotype. J. Reprod. Fert. 92: 187-195.

SUAREZ S. S. 1998. The oviductal sperm reservoir in mammals: mechanisms of formation. Biol. Reprod. 58: 1105-1107.

TALEVI R., GUALTIERI R. 2004. In vivo versus in vitro fertilization. Eur. J. Obstet. Gynaecol. Reprod. Biol. 115S: S68-S71.

Tessler S., Olds-Clarke P. 1981. Male genotype influences sperm transport in female mice. Biol. Reprod. 24: 806-813. 